\title{
North-South Aspects of the Glimate Change Issue: Towards a Constructive Negotiating Package for Developing Countries
}

\section{Joyeeta Gupta}

\section{Introduction}

International discussions on the climate change issue are approaching a negotiating deadlock. ${ }^{1}$ This is because the leadership paradigm underlying the climate change regime is fast evolving into a conditional leadership paradigm. ${ }^{2}$ The leadership paradigm refers to the fact that agreement in the climate change regime was developed on the basis of the principle of "common but differentiated responsibilities and respective capabilities' in the United Nations Framework Convention on Climate Change (UNFCCC). ${ }^{3}$ Under this principle the developed countries would be the first to take action to reduce their emissions of greenhouse gases and developing countries would subsequently follow. However, even though the Kyoto Protocol to the UNFCCC ${ }^{4}$ embodies this paradigm, domestic political events in several countries have resulted in a situation that contradicts its spirit. Several months before the Kyoto Protocol, the US senate made clear that it would be unlikely to ratify any Protocol which set binding targets unless there was clear evidence of the willingness of developing countries to participate meaningfully in the process. ${ }^{5}$ This was partly prompted by growing fears in the US that reducing emissions of greenhouse gases (GHGs) in the domestic context could lead to high domestic unemployment, and that such a risk should only be taken if and when there was some degree of certainty that the developing countries would be willing to eventually take on commitments. The US stance can be viewed in two ways: from a positive perspective, one could argue that all the United States needs is some assurance that the developing countries are serious about taking some sort of action in the future; from a negative perspective it might be said that this position is merely an excuse for postponing action in the US. The fact remains that even if the US president wanted to ratify the Kyoto Protocol, he cannot do so without the support of Congress. The US stance has repercussions on the other developed countries, who are unwilling to ratify if the United States does not do so. ${ }^{6}$ This is an understandable response in that if Europe and other developed countries were to take on unilateral commitments in the absence of ratification by the US (the main emitter of GHGs) the fear is that their domestic economies could suffer disproportionately while the main source of the problem remained unaddressed. Like the United States, the other developed countries are also concerned that the advantages of being 'first movers' in the process of industrial transformation may be difficult to reap if other countries do not eventually join in the regime. Given the contingent nature of willingness to ratify therefore, the entry into effect of the Kyoto Protocol may depend on the signals that the developing countries send.

These concerns prompted discussions on inclusion of an article on the voluntary commitments of developing countries. ${ }^{7}$ After considerable opposition from the developing countries, this article was eventually not included in the Kyoto Protocol. Nevertheless, the issue was raised in several bilateral discussions with different countries. ${ }^{8}$ This increased the pressure on the developing countries, many of whom were upset by this turn of events. ${ }^{9}$ In November 1998, the Argentinian government, which was hosting the fourth meeting of the Conference of the Parties (COP), tried to put the 
issue of voluntary commitments of developing countries on the agenda for discussion. This met with fierce opposition from the developing countries although several developed countries did support the issue. The chair then reserved the right to discuss the issue informally.

During the fourth meeting, the Argentinian government announced that it would adopt voluntary commitments. ${ }^{10}$ Kazakhstan also made a statement to this effect. ${ }^{11}$ Both governments claimed that they would, subject to certain conditions, be willing to reduce their emissions against a base line of their projected growth in emissions. Although this represents an attempt to develop a constructive approach to the problem, it does not provide a useful precedent for dealing with it, because although these countries aim to reduce the growth of their emissions, there is no clear indication of how the base lines are to be drawn, nor is there any indication of the level at which the growth of these emissions will be eventually stabilized.

Against this background, this paper will briefly explore three different approaches that can inform the developing countries' response to these issues, and will recommend which of these options should be adopted. It then explores how that option could be delivered and offers a package of measures which developing countries could bring to the negotiating table. The paper concludes by examining ways in which this negotiating package could be provided with the necessary legitimacy.

\section{Developing Countries: Alternative Responses}

Developing countries have essentially three choices. ${ }^{12}$ The first option is to take the 'principled position' as their starting point. This would mean that developing countries would continue to demand that the North must act first, and unless and until the developed countries can actually demonstrate that they have taken the lead in reducing their GHG emissions to an extent that is compatible with the ultimate objective ${ }^{13}$ of the UNFCCC, the developing countries will not even consider the issue of possible commitments. Under a strict interpretation of this position, the developing countries would also avoid any intermediate discussions of how the regime would develop further. It is unlikely, however, that the developing countries will opt for such an approach: they have clearly expressed their desire to be part of the rule-making process, even though the rules do not directly affect them at present; they are aware of the global interconnectedness of these issues, and do not wish to opt out of the international system. ${ }^{14}$ They are in any event ill-suited to the kind of hard bargaining that the 'principled position' demands. Furthermore, adherence to a strict principled position would be extremely unwise in the context of climate change, as it may give Northern countries the justification to postpone action indefinitely in relation to the issue and focus instead on adaptation to climate change. While there are some economists who argue that this is a cheaper alternative for the developed countries, developing countries are likely to suffer much more since they do not have the resources to easily adapt to the potential effects of climate change.

The second approach is the currently used, strategic, 'business as usual', defensive and reactive approach. This approach is the result of the fact that most developing country negotiators tend to have a handicapped negotiating power, a hollow negotiating mandate, difficulties in developing coalitions with other countries and, hence, tend to react defensively. This strategy is generally characterized by rejecting the ideas from the North, by failing to offer proposals for discussion, and by making few concessions. ${ }^{15}$ It draws upon the national negotiating position adopted in other issue areas and hence, being tried and tested in these areas, appears to be legitimate. Given the limited resources available to developing countries, this tends to be the generally adopted negotiating strategy. However, it is a strategy with disadvantages. First, such an approach does not clearly articulate what the developing countries are willing to provide in exchange for what the developed countries will do. In other words, there is no give and take, and hence after a while the developed countries get the feeling that they are the parties that have to do all the work. Second, developing countries tend to lose out in negotiations since they are less well prepared with alternative suggestions. If they do not know what they want and how they can develop an effective strategy to secure what they want, they may not get what they want. Third, because developing countries tend to use defensive strategies, developed countries assume that this culture will prevail, which accounts for the increasing lack of confidence amongst the developed countries as to when or whether the developing countries will adopt some concrete commitments. Although understanding and respecting the conditions under which developing countries prepare their defensive negotiating strategies, it is suggested that these strategies have been to some extent responsible for the negotiating bottleneck that the climate change regime now faces. While this does not in any way imply that the US is right in holding the regime hostage to meaningful participation by developing countries, it is important to reiterate that if the regime does not develop further, those most at risk are the developing countries. One only has to look at the calculations about which region is most likely to suffer as a percentage of regional GDP to see the enormous implications for these countries. ${ }^{16}$

The third approach which might be taken is the constructive package approach in which the developing countries take on a proactive role. Here, the developing countries would discuss among themselves how they would wish the regime to develop further and would produce concrete suggestions. This strategy calls not only for creative thinking, for the development of innovative ideas, but also for the lobbying of domestic actors and other international partners to ensure that there is broad-based support. In short such an approach is labour intensive and, if inadequately discussed and supported internally and internationally, it could be very risky. It is a risky strategy internally, in that if there is inadequate support domestically, the negotiator risks 
losing his or her job. It is risky internationally, in that if it is poorly articulated and negotiated, the negotiating process may lead to a situation in which the final consensus does not resemble the initial proposal of the developing countries.

This article, while recognizing the advantages of a defensive approach, proposes that the constructive approach should be followed, and presents a proactive package of ideas that could be used by developing countries to negotiate their case and by developed countries to encourage the proactive participation of developing countries. However, it is important to emphasize that developing countries should not engage in discussion under a constructive approach in the international treaty negotiations until they have taken the necessary steps to avoid the risks attached to such an approach. ${ }^{17}$ These steps will be considered in the concluding section, 'Towards Creating Legitimacy'.

\section{The Constructive Approach}

The suggested approach is therefore for developing countries to develop a package of options that could be seen as their 'meaningful' contribution to the climate change issue and as their demands in relation to the issue. This strategic method may surprise the US government which has thus far not articulated what 'meaningful participation' is despite an announcement that 'the Kyoto Protocol does not meet our requirements for developing country participation'. ${ }^{18}$ By taking control over the discussions, the developing countries could articulate meaningful participation from their own perspective. This may help break the deadlock that is threatened by the first option and perhaps even hoped for by industry. Moreover, while not denying the legitimacy of the developing countries' position, its effectiveness in contributing to an international regime that calls for farreaching reductions in the developed countries is questionable.

As has been previously argued, the developing countries need to adopt an ABCDE policy. Such a strategy would imply that developing countries should develop an active and effective negotiating role, should emphasise the boomerang effect of the potential impacts of climate change on developing countries, should exploit their comparative advantage and their demographic power in the negotiation situation and should try and negotiate a package that takes into account the concerns of all the key groups of developing countries. ${ }^{19}$

On the basis of over 250 interviews, I have sought to develop a package of options that developing countries could attempt to negotiate. This package is based on trying to develop a compromise position between the developing and developed countries. Earlier versions of this package have been presented at international academic and policy meetings in London (June 1998), ${ }^{20}$ Nairobi (July 1998), ${ }^{21}$ New Delhi (September 1998), ${ }^{22}$ Utrecht (October 1998), ${ }^{23}$ Buenos Aires ${ }^{24}$ and Chile (November 1998), ${ }^{25}$ and Milan and London (March 1999). ${ }^{26}$

(c) Blackwell Publishers Ltd. 1999

\section{Differentiation of Countries}

Some researchers would argue that in order to address the climate change problem, only a few large emitters from the South need to be involved in the process. This is also probably the rationale behind the US position that key developing countries need to show their willingness to participate meaningfully in the process. While this may be accurate from a purely technical perspective, it is more than likely that the rest of the developing countries would suffer quite substantially from the consequences of such an approach. The package offered below therefore seeks to take into account the concerns of the different negotiating blocks in the climate change negotiations. ${ }^{27}$

The developing countries consist of about 134 members (the G-77 group) that are parties to the Convention. Interviews reveal that most negotiators from this group, while acknowledging that they have internal differences, nevertheless believe that they should negotiate as a unified group in order to resist pressure from the developed countries. Yet the G-77 seems to be fragmenting into subgroups with different negotiating perspectives. Thus China and India tend to focus on equity arguments and the need for developed countries to fulfil their obligations before the developing countries come on board Philippines, Argentina and Costa Rica are part of another emerging group who want to demonstrate that much action is already being taken. The small island states are angry, the oil producers defensive and the smaller countries are accommodating, arguing that it is sensible to take what they can get. Despite this tendency towards fragmentation, it is suggested that these differences of emphasis can and should be united into a strong negotiating strategy that could be presented by the group as a whole. However, in forging a common negotiating strategy it is important to identify the differing concerns confronting the various sub-groups. There are essentially five categories of developing countries: the newly industrializing countries, the oil exporting countries, the middle income countries, the small, poor and vulnerable countries and the 'giants'.

The newly industrializing countries are developing rapidly. Some have already obtained OECD membership, while others hope to follow. Although some of these countries are at present in recession, discussions with their negotiators indicate that many of them are prepared to ultimately accept responsibilities that match their new status, although they will resist such measures for as long as possible. Such countries would perhaps be willing to accept commitments in line with the commitments of the Annex B countries on the condition that they receive a grace period, or an alternative base year.

The oil exporting countries are also among the richer developing countries, but they have a specific problem in that they are economically dependent on oil exports. They are consequently reluctant to support far-reaching measures to reduce GHG emissions since they are afraid that this will have a highly negative impact on their economies. They have therefore opposed binding obligations for developed countries in the past. In 1995, the G-77 
decided to conduct certain crucial negotiations without the oil exporting countries, and they formed the green G-77 in order to push for harder measures. Since then, the oil exporters have modified their strategy. They are now trying to find other ways and means of dealing with the climate change issue without necessarily suffering economically. In interviews, some of their negotiators have suggested that they could support tougher measures for the developed countries if the developed countries were to adopt a carbon tax and phase out subsidies to the fossil fuels. This, they argue, would lead to an increase in the demand for oil. There is however no consensus among the oil exporters on this issue. Ultimately, this group will be able to prevent binding measures only to the extent that the developed countries do not themselves want such measures. If and when the developed countries decide to focus on phasing out the use of fossil fuels these countries will be badly affected, and hence they need to invest in diversification of their production base.

The middle income countries are countries that do not yet have a solid institutional structure but whose economies are growing steadily. Their pollution levels are also increasing, and they are likely to be vulnerable to the climate change issue. These countries need to explore the potential of making the Clean Development Mechanism ${ }^{28}$ work well both in terms of the goal of sustainable development and in terms of securing financial assistance for promoting technological advancement and reduction of GHG emissions in relation to each project. They also need to look at their policies and see where there is potential for changing course towards a more sustainable development path.

There are a large number of relatively small developing countries whose national income is quite small and whose emission levels are fairly low. They are caught between a vague realization that climate change could have serious impacts on their countries, and their current long list of domestic priorities. The 42 small-island states have been demanding since the early 1990s that serious emission reduction measures should be taken by governments. The Alliance of Small Island States (AOSIS) prepared a draft text for a protocol demanding a $20 \%$ reduction of GHG emissions by 2005 by Annex I countries. In addition these countries have been requesting assistance for adaptation measures, but under the present financial arrangements, no assistance for adaptation will be provided for some time to come. Under the Kyoto Protocol, a part of the proceeds of the Clean Development Mechanism projects will be used to finance adaptation projects in the most vulnerable countries.

The large developing countries are confronted with the dilemma of pursuing economic growth without increasing their already high GHG emission levels. Although this problem does not come into play in the short-term, these countries fear that it will soon be a major issue, especially given the concerns of the US Senate. Since the climate change issue is a low priority issue on the domestic agenda, and there is limited research on the issue, the negotiators from these countries are affected by a handicapped negotiating power that both hampers the horizontal development of the regime and its vertical domestic implementation.

\section{Elements of a Package}

This section presents a possible negotiating package that developing countries could discuss and use as a basis for developing their negotiating position. As mentioned earlier, the package builds on interviews with negotiators and policymakers from the South and the North. It consists of nine elements: the cool air approach, the cool indicator approach, policies and measures reports, the Clean Development Mechanism, the grace period, the flexibility tax, the assistance indicator, the non-compliance fund and the G-7 quick communication channel.

\section{The Cool Air Approach}

Although the climate change regime is developing pragmatically, with countries promising what they can do, eventually the commitments will have to be shared. Without prejudice to this, it is proposed that for a start there should be a recognition of the default principle of a minimum emission level per person. The 'cool air' approach describes the concept whereby countries that emit less than a 'floor' (minimum) emission level should be entitled to some benefits under the treaty, including: (a) the right not to be subject to any commitment under the treaty, and (b) the right to either trade the unused portion of their emissions under the international trading regime or the right to priority in receiving the funds under the adaptation fund.

The minimum emission level would be defined on a per capita basis. However, relevant national circumstances would need to be taken into account in defining such a minimum. These may include criteria such as the availability of alternatives and/or the relevant climatic and geographical conditions. The minimum would not be the maximum to be allowed, merely the floor. Once the minimum was reached, it does not imply that commitments would follow.

The background to this proposal is that the Kyoto Protocol allows trading under Article $17 .{ }^{29}$ Under this mechanism the (developed country) Parties listed in Annex B will have GHG emissions allowances (assigned amounts), that are equivalent to their commitments under the Protocol. Parties that do not use their allowances during the first commitment period can sell their surplus to Parties that have exceeded the allowance. How the allowance will be established and what rules must be applied in case of non-compliance will be further discussed by the Subsidiary Body on Scientific and Technological Advice and the Subsidiary Body on implementation at the preparatory sessions of the COPs. ${ }^{30}$

Allowance allocations are a controversial issue. The theory of emissions trading is that emission levels are allocated among countries, and countries that underuse their permits may sell to overusers. This provides underusers with a reward and overusers with an incentive to minimize their emission levels. Since the market determines the price of the permits, such a system can 
efficiently reduce emissions at the cheapest costs. While the theoretical efficiency of the system is not affected by the initial allocations of emission rights, the initial allocations are critical to whether such a system would be acceptable to countries or not. If the initial allocation levels are set at a particular historic year, eg 1990 ('grandfathering'), this allows the status quo between countries to be maintained. This option is relatively attractive to the developed countries, as it rewards, as they see it, the 'first movers and hard workers'. The developing countries, on the other hand, see the grandfathering system as rewarding the polluters and punishing the poor, who would have to pay substantially to get emission rights. ${ }^{31}$ They would prefer allocations to be made on a per person/per hectare basis, or on the polluter pays and ability to pay principle.

Until Kyoto, there was no consensus on this issue. Article 17 of the Kyoto Protocol, however, permits emission trading between developed countries against the allocations (or targets) as agreed upon by Annex B countries. These targets are not based on any criteria other than the criteria of political feasibility, and to some extent contain an element of initial grandfathering. Until 2008 there are no targets for these countries; after 2008 there are targets but these relate to emission levels in 1990 (and perhaps 1995). Some developed countries are even allowed an increase in their emissions. The 'cool air scheme' offers certain advantages:

- It would ensure that the most vulnerable countries have access to assistance. The countries that would benefit from such a scheme are those with low emissions who are particularly vulnerable (due to their low income levels) to the potential impact of climate change, in particular, the 42 small island states and the 50 or so poor African states. The underlying principle that these countries should not have to suffer the consequences of climate change without some assistance has been accepted in the Rio Declaration and in the UNFCCC. ${ }^{32}$

- The scheme represents a compromise between developed and developing countries. More radical suggestions have indeed been made, such as the proposal made by the Brazilian government which would take past emission levels into account in determining how emission allocations should be shared, the proposal of the Centre for Science and Environment in New Delhi which argues that an equitable sharing is the only possible way, and Contraction and Convergence proposal of Globe 1998, also based on equity. ${ }^{33}$ However, these proposals have met with resistance and scepticism from the developed countries since they involve a large transfer of resources to the poor countries. The minimum emission level proposal is a compromise between the positions, which acknowledges the validity of the convergence arguments, while accepting that the industrialized governments would, even if they wanted to, never be in a position to get such a proposal accepted by their electorates. The cool air approach is made on the basis of three principles that western countries and their populations accept: (i) the polluter pays principle, (ii) the human rights principle and (iii) the equality of opport- unity principle as opposed to the equality of outcomes principle. How can any western government deny the 'minimum' needed for a basic dignified life? The proposal is also a compromise in that it accepts that there needs to be a cut-off year so that the scheme is not a carte blanche for population growth. But the cut-off year must be reasonable in order not to penalize future generations, in accordance with the principle of sustainable development.

- The scheme also allows the very poor developing countries to learn to trade with the new currency of the future - emission permits.

- The scheme helps to break the new North-South divide that was created by allowing emission trading only among the developed countries. It also helps those countries that are likely to receive the least funding under the Clean Development Mechanism (CDM). ${ }^{34}$ There is a growing fear that the continent of Africa may not be able to attract large sums of money through the CDM. This fear is based on the projects that actually were developed in the Activities Implemented Jointly phase. ${ }^{35}$ Recent reports indicate that very few Activities Implemented Jointly Projects have been developed in Africa. Of the 74 reported projects in 1997, only one took place in Africa. ${ }^{36}$ A year later the number had increased to two, although the total number of projects had increased to $123 .^{37}$ The projects are mostly agriculture and/or forestry related and some are in the area of renewable energy projects. It has been argued that the economic criteria underlying the AIJ/CDM may lead to the exclusion of an entire continent. ${ }^{38}$

- It seems quite unethical to invite this large group of countries to the international negotiations, only to let them know that they may suffer seriously from the effects of the problem and not to offer them any assistance. The cool air option offers a way out of this dilemma.

- The cool air proposal is to some extent in line with the European Union proposals to develop differentiated targets for member states, whereby a quantitative sectoral approach is to play an important role in attaining burden differentiation which will then be reflected in the decisions and conclusions of the Council of Environmental Ministers. ${ }^{39}$ One of the important aspects of the EU proposal is that the 'national circumstances' are quantified and hence made the subject of quantitative and principled discussion. The cool air approach attempts to do just that.

- Finally, such a scheme will not expose developing countries to the argument that they need to address equity concerns within their countries before they can demand it internationally. This is because although the gap between rich and poor is large in most developing countries, most of these countries have policies aimed at poverty abatement.

The disadvantage of the cool air scheme is that it creates a new flexibility mechanism. Opponents of the scheme are likely to argue that this creates a new form of 'hot air'. They are referring to the fact that some developed countries are allowed an emission level in 2008 that appears to be higher than current prognosis predicts. For example, it is unlikely that Russian emissions in the 
period 2008-2012 will be anywhere near the stabilization target they have been allocated. It is more than likely that their emissions will be up to $30 \%$ below that level. ${ }^{40}$ Thus any trading with Russia will be seen as trading in 'hot air' a term that has been used in this context to describe a notional 'surplus' created by overly high initial allocations. The extent to which this could occur depends mainly on the economic growth of these countries during the next 10 years. However, hot air is distinct from cool air, because it concerns countries that fall below a minimum per capita emission level; whereas the hot air issue concerns countries that have an excess emission level. Furthermore, the cool air approach concerns countries that are most vulnerable to the climate issue. Finally, why should some countries be allowed to benefit from hot air and others not. ${ }^{41}$ From the point of view of an environmentalist and a lawyer, a regime without loopholes is the best possible regime. But political scientists would argue that the main purpose of a regime is to set up institutions and to send signals to industries and government to change their method of production and consumption. ${ }^{42}$ If that is the case, such a cool air approach has the advantage of involving people in these countries in also thinking about the potential ways to change their development patterns in the future.

A further problem associated with the cool air concept relates to the accuracy of calculations, and liability for miscalculations. Many developing countries do not have proper institutional structures, and it would be unwise and unfair to burden them with the responsibility of ensuring that the emission reductions are genuine by developing a 'seller beware' approach.

If trading in cool air was unacceptable, then the alternative approach of linking such a concept to adaptation funds could be used. This would allow countries that fall below a minimum level of emissions to be given priority in receiving funds from the adaptation fund established under Article 12.8 of the CDM.

\section{The Cool Indicator Approach}

A 'cool indicator' is a simple indicator which could usefully be adopted by the developing countries. Two such indicators - a GDP related indicator and a subsidy related indicator - will now be explored.

A GDP related or a government spending related climate change indicator needs to be developed. Such an indicator would indicate what percentage of the GDP or government expenditure is spent on climate change related measures. It would be easy to develop as the necessary information is readily available. This indicator would enable each of the developing country parties to indicate the measures they are currently undertaking. Most developing countries spend money on afforestation policy, fuel-switching, energy efficiency or renewable energy, as was clearly indicated by the presentations of developing country NGOs and negotiators during the meetings of the subsidiary bodies in October 1997 and during the December 1997 negotiations. ${ }^{43}$ Although there is very little research on the subject, many developing countries probably spend comparable amounts as a per- centage of GDP on climate change related measures. Such an indicator would therefore help to provide the evidence of meaningful participation that the US senate apparently needs. There are, however, a few problems with such an approach. First, a GDP related indicator is no proof of actual effect. That is true, but such an indicator has been used to show Official Development Assistance in the past and has its own value, however limited. Second, it is always difficult to know what can be included and what cannot; however, this is true for all broad indicators.

Another indicator that could be useful is one that reports on the percentage of subsidies that are being phased out in relation to fossil fuels and, if relevant, in relation to agriculture. India, Mexico, South Africa, Saudi Arabia and Brazil have already cut fossil fuel subsidies substantially. ${ }^{44}$ Many developing countries have undertaken measures to phase out the subsidies in relation to various relevant sectors, primarily as a result of the introduction of Structural Adjustment Programmes or other domestic policies. Reporting on the phase out of these subsidies in relation to subsidy levels in 1990 may also be of vital interest. It is important to note here that we are talking about an indicator of actual progress that can be reported on by developing countries, not about their future commitments.

\section{Policies and Measures Reports}

Middle and high income developing countries could go a step further and report on on-going policies and measures (PAMs) that (directly or indirectly) take the climate change issue into account (for example in relation to Article 12 of the United Nations Convention on Climate Change). If one examines the national policies in relation to energy, transport, agriculture, one can identify several measures that are being taken by developing countries to improve demand-side management, promote renewable energy, promote public transportation etc. NGOs and industries are also initiating certain practices and policies that can stimulate a change in behaviour and reduce the relative growth in emissions. ${ }^{45}$ Ultimately, any correction or improvement made to existing policies that avoid emissions should be reported upon just to demonstrate the degree to which climate change issues are being directly or indirectly taking into account in the process. In fact, the Climate Convention calls on all governments to communicate their national policies and measures, and hence this principle is consistent with existing commitments.

The advantages of PAMs reports are as follows. First, several of the middle income developing countries are already taking some sort of measures; it would make sense to make political capital out of these measures by making them more visible to the Northern countries. Second, such policies help to indicate the areas in which Clean Development Mechanism projects are likely to be welcome. Third, such reporting could assist developing countries in convincing the North that they are taking the issue seriously within their limitations. Fourth, in many cases, the developed countries themselves examined other policy areas to see what the impact on greenhouse gas emissions were likely to be. Thus, for example, 
the Netherlands examined the existing energy conservation policies and calculated the potential impact of such policies on GHG emissions. Many countries thus calculated the incidental benefits of existing policies in other subject areas to check what the potential impacts on their GHG emissions would be. This was a first step towards developing new climate change policies.

However, such an approach is not without its disadvantages. It calls for identifying experts who will spend time examining all the policies to see which can have a beneficial impact on climate change. This implies diverting resources and manpower from other priorities in order to fulfil the reporting requirements. In response, however, the reporting requirements in relation to such policies need not be complicated and stringent; instead, a format should be adopted which allows these countries to make a quick estimate of how their policies impact on climate change.

\section{The Carrot: The Clean Development Mechanism}

Without prejudice to the continuing debate in developing countries on the advantages and disadvantages of the Clean Development Mechanism (CDM), this section presents one key idea. The CDM can potentially provide opportunities for the developing countries to participate in a meaningful manner in the climate change regime. It will perhaps be of most value to the middle and high income countries of the South. Article 12 (2) states:

The purpose of the clean development mechanism shall be to assist Parties not included in Annex I in achieving sustainable development and in contributing to the ultimate objective of the Convention, and to assist Parties included in Annex I in achieving compliance with their quantified emission limitation reduction commitments under Article 3 .

\section{Article 12 (3) states:}

Under the clean development mechanism: (a) Parties not included in Annex I will benefit from project activities resulting in certified emission reductions; and (b) Parties included in Annex may use the certified emission reductions accruing from such project activities to contribute to compliance with part of their quantifies emission limitation and reduction commitments under Article 3, as determined by the Conference of the Parties serving as the meeting of the Parties to this Protocol.

Under the Article, Parties may voluntarily participate in the process, there must be real, measurable and long term benefits, and the reductions should be additional to any that would occur in absence of the project. The emission reductions can be banked up to the first commitment period. Part of the proceeds are expected to be used for administrative and adaptation costs. The article on the Clean Development Mechanism in developing countries calls for a small sum of the proceeds to be left aside for assisting the most vulnerable countries. ${ }^{46}$ There is an executive board to manage the mechanism. One crucial aspect of CDM development requires consideration. The argument is that there should be potential for the unilateral generation of credits and for credit sharing. This should provide investors within the developing countries with an incentive to explore the opportunities for reducing GHG emissions by improving on domestic projects. Clearly such projects should also be formally registered with the executive board of the mechanism. If such projects are accepted as CDM projects, it should be possible to trade the certified emission reductions thus achieved internationally. This will lead to demand (rather than supply) driven projects, higher returns on the credits for developing countries, reduced transaction costs for developed countries and the creation of positive incentives for developing country industries to modernize.

\section{The Grace Period}

The grace period refers to an extra period of time that is made available to different groups of countries for fulfilling their obligations. The concept was inspired by the Montreal Protocol which gave developing countries ten years in which to fulfil their obligations. ${ }^{47}$ The climate change regime arguably allows the developed countries a 16 year grace period (1992-2008) before legally binding emission limitation and reduction commitments become applicable to them (depending on how the period is defined). It might therefore be appropriate for developing countries that reach a certain threshold level of national income and that emit more than a critical emission level per capita to similarly have a grace period of some years, before legally binding objectives become applicable to them. The attractions of such an approach are that it would provide the developing countries with a measure of protection against growth being followed by immediate economic collapse, and would make it easier for these countries to accept commitments. The disadvantage of grace periods is that they postpone the adoption of measures to reduce GHG emissions.

\section{The Flexibility Tax}

Under the Kyoto Protocol, there are three co-operative mechanisms (the 'flexibility mechanisms'). These are: trading of emission credits amongst the developed countries in Annex B of the Kyoto Protocol; the clean development mechanism, which is an instrument to promote cooperation between the developed and the developing countries; and joint implementation with other developed countries, ie with those countries with economies in transition. The flexibility tax refers to a small tax to be levied on all three co-operative mechanisms under the Kyoto Protocol to be paid by the investor.

The advantages of this tax are as follows. As mentioned earlier, under Article 12 (8) of the Kyoto Protocol, a portion of the proceeds of CDM projects is to be kept aside for adaptation purposes. This suggests that the costs of CDM projects are likely to increase relative to Joint Implementation and emissions trading costs, since no similar article is included in the other flexibility mechanisms. This indirectly constitutes a tax on the cooperation between developed and developing countries, which may reduce the attractiveness of CDM projects in relation to other flexibility mechanisms, thus reducing the amount of money made available for adaptation purposes. With a flexibility tax, however, all flexibility mechanisms would generate a percentage of the proceeds to be set aside to fund adaptation activities in the most vulnerable countries, thereby ensuring that all three mechanisms become comparable in terms of costs for the investors. Furthermore, by levying the flexibility tax 
on all three mechanisms, the total amount of money generated for adaptation purposes would be increased, the principle being that to the extent that developed countries do not take measures domestically, there is a polluter pays tax which is imposed on the flexibility mechanisms. (The tax would not apply when developing countries develop CDM projects unilaterally, only to the international transfers). Finally, and most importantly, the tax would provide an incentive for the developed countries to reduce emissions domestically.

\section{The Assistance Indicator and Graduation to Annex II}

The assistance indicator refers to a reporting requirement whereby the developed countries (excluding the countries with economies in transition) would report on the assistance they provide to the developing countries in terms of an indicator. At present, the obligations of developed countries to provide developing countries with financial and technological assistance are vaguely worded. A GDP related climate change assistance indicator would show with some clarity the kind of assistance being provided, for example, under Article 10 of the Kyoto Protocol. There are several advantages of developing such an indicator. First, when such an indicator is placed next to the Official Development Assistance indicator, it would show that the assistance is, indeed, measurable and additional. Second, most developed countries already make large sums of money available to developing countries in the context of various projects. The indicator would help to make the assistance easily visible. Furthermore, companies that have invested in Joint Implementation and Activities Implemented Jointly Projects in the last eight years, may not be able to get any credit for the actions they have taken thus far. They could, however, report their activities for inclusion in such an assistance indicator. Fourth, it would help the psychological development of the regime. Fifth, it is relatively easy to develop such an indicator. While it might be argued that an assistance indicator shows only money made available, and not the impacts made, this objection is not insurmountable.

While such an indicator applies only to the richer developed countries at present, there should be a process of graduation by which the Central and Eastern European countries should have a grace period which is then followed by a period in which they are also obliged to provide quantified assistance to the developing countries, following which these countries should also become members of Annex II of the UNFCCC.

\section{The Non-Compliance Fund}

The concept of a Non-Compliance Fund builds on the ideas of the Brazilian Proposal on the Clean Development Mechanism. ${ }^{48}$ Basically, it means that all countries that do not comply with their legally binding emissionrelated commitments and who cannot purchase credits on the international market, should be obliged to pay a fine that finances a technology co-operation fund. Within a period of, for example, three months following the end of the first commitment period, parties will be encouraged to shop around for credits that they can purchase in the international market. If such credits are not avail- able, defaulting parties will be fined. The advantages of this proposal are that it is consistent with the polluter pays principle, it pushes up the price of credits, and ensures that the system is effective. If there were no noncompliance mechanisms, the entire system of trading would collapse. The disadvantage of such a system is that it would not be fair to countries with weak organizational structures who are perhaps already in debt. To meet this problem, it is suggested that countries with established and secure institutional mechanisms be fined under the Non-Compliance Fund, whereas countries with less established and weak institutional structures should be dealt with by the kind of non-confrontational Non-Compliance Mechanism that has been developed in the ozone depletion regime. If it is the intention of the developed countries to encourage the developing countries to take on commitments while their institutional structure is still weak, then it is vital that the developing countries are not penalized if they cannot effectively implement for lack of institutional mechanisms.

\section{The G-7 Approach - Quick Communication Channel} The above measures would provide an effective and fair mechanism that enabled the developing countries to participate and that helped keep all countries on board the regime. But in the final analysis, it is the emissions of China and India that are going to be of crucial importance. These two countries with their huge populations, abundance of natural resources and desire for growth are destined to be the world's largest consumers of energy, responsible for a substantial portion of global GHG emissions. If they are not actively involved in some way at the highest possible level, the problem may soon get out of hand.

At present these countries have many pressing problems, and the interest shown by their governments in the regime is nominal. Furthermore, they tend to get mixed signals about what is considered important from the North. The liberalization message often competes with the environmental message. It is proposed, therefore, that these two countries should be invited as observers to the G-7 meetings to discuss these issues in an integrated manner.

There would be several advantages to such an approach. First, it would ensure that an integrated and coherent message is given to the leaders of these countries. Sources state that the reason that the Clinton administration in the US started to think seriously about domestic targets is because of the pressure put by the G7 at their summit in 1997; in other words, the communication channel of the G7 clearly seems to have some effect. Second, the Summit documents reveal that the most powerful countries talk about the future of the entire globe, for example, in referring to the steps needed

to shape the forces of integration to ensure prosperity and peace for our citizens and the entire world as we approach the twentyfirst century. We have agreed to work closely with all willing partners in fostering global partnership for peace, security, and sustainable development that includes strengthening democracy, and human rights, and helping prevent and resolve conflicts. ${ }^{49}$

These discussions presently take place without any representation from the South, when in fact they could be 
usefully enhanced by contributions from China and India. Third, there may be incidental advantages in terms of improving global security. At the same time, the developed countries could send out one comprehensive message about how the key issues of security, peace, environment and economic advance can be addressed.

\section{The Package Summarized}

Table 1 illustrates the elements of the proposed negotiating package as they would apply to the different groups of countries within the regime. In essence, this package implies that as countries become richer, they initially have a grace period and then legally binding commitments become applicable, followed by reduction commitments and stabilization commitments. This is shown graphically in Table 2 .

This paper sets out proposals for developing a scheme to involve the developing countries. It does not attempt to define minimum emission levels or levels at which countries move from one group to another. It merely sketches out a possible scenario for the development of the regime. The proposals involve a give and take between developed and developing countries. Thus, for example, the cool air proposal provides credits to developed countries without any transaction costs, besides making the regime somewhat fairer to the smaller developing countries. The proposals on the cool indicator, PAMs reports and the CDM may well be attractive to the developed countries. Although less acceptable to the developing countries, they would in fact be relatively painless for them, except perhaps in political terms. The issue of the grace period may be equally unacceptable to all groups of countries, but perhaps for different reasons. For the high income developing countries, the period may appear too short; for the developed and other developing countries, the period may appear too long.

The flexibility tax may initially appear unattractive to the developed countries at first sight, but since it provides an incentive for increasing domestic innovation, it may not prove to be unacceptable. The non-compliance fine, again superficially unattractive, has the advantage of making the basis for emissions trading more secure. The assistance indicator should not, in theory, be painful, since most of the developed countries are already assisting developing countries, and that assistance is not as visible as it could be. The G-7 dialogue proposal would cost no more than the political willingness to engage in constructive discussion with these countries and to try and deal with the problems of security, poverty development and environment in an integrated manner. There are probably many variations possible in the development of such a package. This is merely one suggested approach.

\section{Towards Creating Legitimacy}

As discussed above, a constructive approach exposes the developing countries to certain risks. If poorly articulated and negotiated, proposals run the risk of being stripped apart, and negotiators risk losing their jobs. This section explores how the negotiating package can acquire the legitimacy needed to avoid these pitfalls.

It is vital that before such a package is negotiated, it is extensively discussed with all developing countries and within the developing countries. To begin with the latter first, developing countries need to ask their researchers, NGOs and industry to analyze the implications of such a package and then to see how it can be modified to adequately take care of their interests. There should also be a clear fall-back position negotiated in advance beyond which the developing countries refuse to go. The package should not be unreasonable. The negotiators should also try to check whether the negotiating position is in line with precedent, and other domestic policies. They need to realize that they have to develop the package in such a way that they offer something in return for the action that is taken by the North. Domestic

Table 1. The negotiation package to involve developing countries

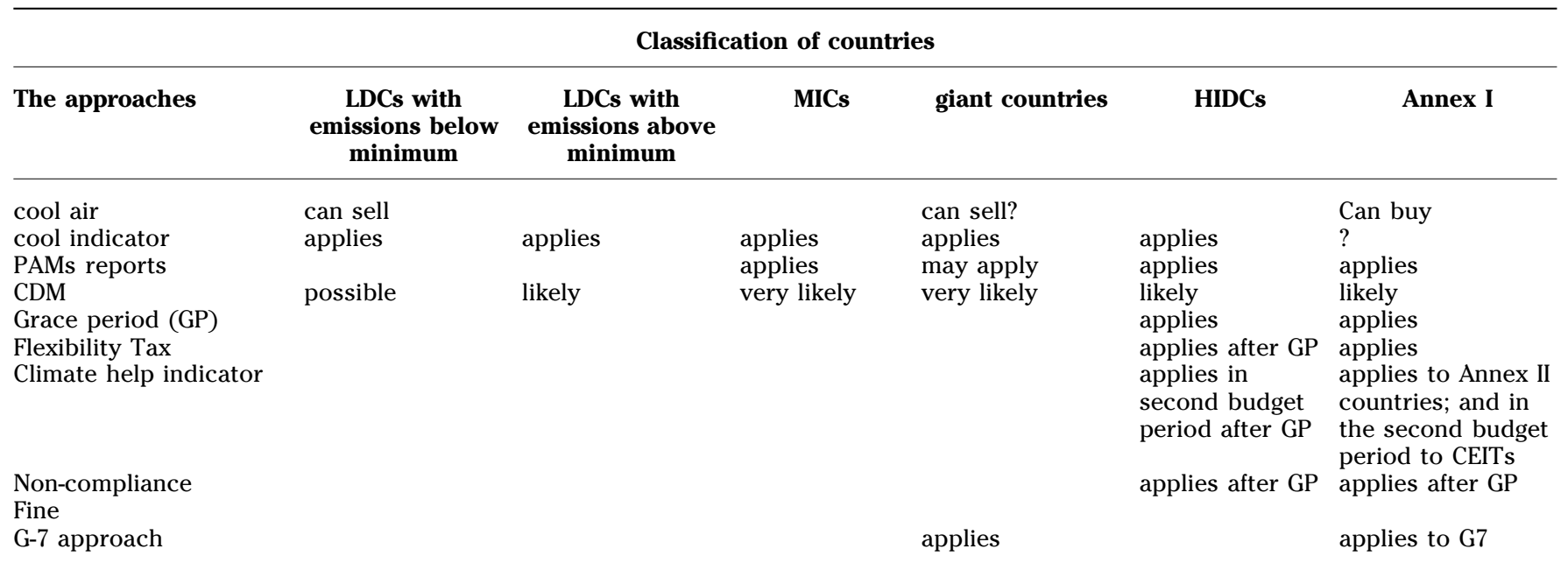

Legend: LDC - less developed country; MIC - middle income country; HIDC - high income developing country; CEIT - countries with economies in transition

(c) Blackwell Publishers Ltd. 1999 
Table 2. Articulating 'common but differentiated responsibilities'

\begin{tabular}{|c|c|c|c|c|c|c|c|}
\hline $\begin{array}{l}\text { The } \\
\text { approaches }\end{array}$ & $\begin{array}{l}\text { Cool air: } \\
\text { operative } \\
\text { until the } \\
\text { minimum } \\
\text { emission per } \\
\text { capita level is } \\
\text { arrived at }\end{array}$ & $\begin{array}{l}\text { Indicators: } \\
\text { operative for } \\
\text { all parties }\end{array}$ & $\begin{array}{l}\text { Menu of PAMs: } \\
\text { operational } \\
\text { when income } \\
\text { and emissions } \\
\text { are at the } \\
\text { middle level }\end{array}$ & $\begin{array}{l}\text { Grace period } \\
\text { operative from } \\
\text { the moment } \\
\text { that critical } \\
\text { per capita } \\
\text { emission levels } \\
\text { are reached }\end{array}$ & $\begin{array}{c}\text { LBC: } \\
\text { operative } \\
\text { from the end } \\
\text { of the grace } \\
\text { period }\end{array}$ & $\begin{array}{l}\text { LBRC: } \\
\text { operative from } \\
\text { no later than } \\
\text { the moment the } \\
\text { maximum per } \\
\text { capita emission } \\
\text { level is reached }\end{array}$ & $\begin{array}{c}\text { LBSC: } \\
\text { operative when } \\
\text { an acceptable } \\
\text { per capita level } \\
\text { is reached }\end{array}$ \\
\hline
\end{tabular}

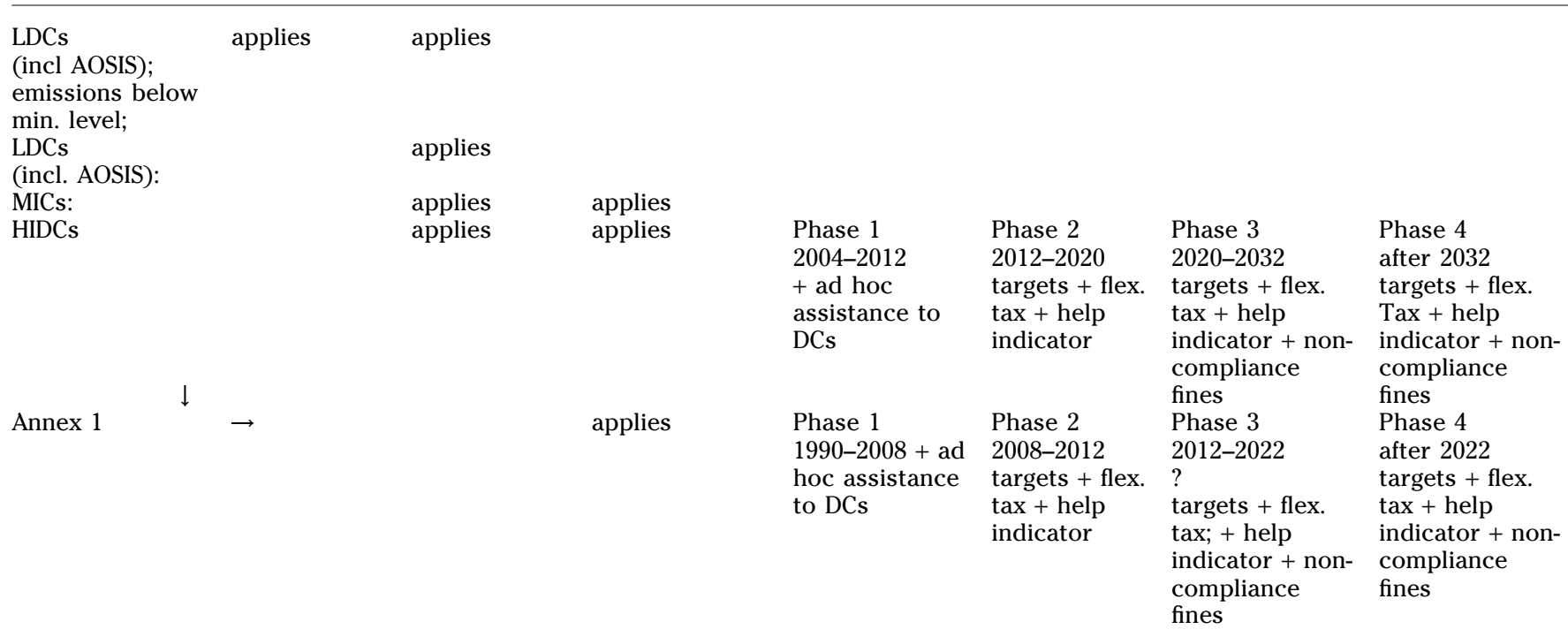

Legend: LBC - legally binding commitments; LBRC - legally binding reduction commitments; LBSC - legally binding stabilisation commitments

legitimacy is a vital first step towards discussing such a package with other countries. In doing so, there must be a willingness to ensure that the system is internally consistent, accommodating the concerns of other countries and that there is transparency and clarity, in order to dissipate the angst that seems to underlie most developing country responses to developed country proposals. ${ }^{50}$

The principle of 'common but differentiated responsibilities' is a key feature of the Kyoto Protocol. However, it is still in its infancy. This analysis indicates that the dynamics of the participation of developing countries in the international negotiation process is such that they are unlikely to wish to develop a proactive approach to defining such participation. Nevertheless, now is the time for developing countries to take on a proactive role and to define such participation in a manner that involves all the parties. This approach is essential if the process is to move forwards; for should the developed countries decide to focus only on adaptation to climate change within the domestic contexts, the developing countries will suffer the most. Having said that, the industrialized countries also need to examine their own measures and see if these indeed add up to 'meaningful participation'.

\section{Notes}

1. See Joyeeta Gupta, The Climate Change Convention: From Conflict to Consensus? (Dordrecht, Kluwer Academic Publishers, 1997) 187-189.
2. See Joyeeta Gupta, 'Leadership in the Climate Regime: Inspiring the commitment of developing countries in the post-Kyoto phase' RECIEL 7:2 (1998) 178-188; Joyeeta Gupta and Nicolien van der Grijp, 'Leadership in the Climate Change Regime: The European Union in the Looking Glass' International Journal on Environment and Pollution 11 (1999), forthcoming.

3. 1992, New York, in force 24 March 1994, (1992) 31 ILM 849.

4. Kyoto Protocol to the United Nations Framework Convention on Climate Change (1998) 37 ILM 22; (the text is also available at the website of the climate secretariat, http://www.unfccc.de)

5. See eg 'Clinton Presents Emission Plan', The International Herald Tribune, 23 October 1997 at 3; William Jefferson Clinton, Remarks by the President on Global Climate Change at the National Geographic Society on 22 October 1997, also available at <http://www.whitehouse.gov/Initiatives/Climate/ 19971022-6127.html> and M. Albright, Earth Day speech, Museum of Natural History 21 April 1998.

6. Several European Union country negotiators and negotiators from the other developed countries have explained that under current circumstances their governments are unlikely to ratify the Kyoto Protocol until the US does so.

7. See eg Farhana Yamin, 'The Kyoto Protocol: Origins, Assessment and Future Challenges' RECIEL 7:2 (1998) 122-123.

8. See M. Albright, n 6 above.

9. See eg Emilio Lèbre La Rovere, 'Stalemate in Climate Protection', Tiempo 30 (1999) <http://www.cru.uea.ac.uk/tiempo/ floor $0 /$ recent/issue30/t30a1.htm>.

10. See also Address by the President of Argentina, Report of the Conference of the Parties on its Third Session, at Kyoto, FCCC/CP/1998/16 Annex 1.

11. See the speech of Dr Seribek Zh. Daukeev, Minister of Ecology and Natural Resources of the Republic of Kazakhstan and head of delegation to COP-4, Buenos Aires, 12 November 1998.

12. These are discussed more fully in a paper submitted for publication to the International Journal on Sustainable Development

13. See Art 2, FCCC.

14. See A. Mazrui, 'Exit Visa from the World System: Dilemmas of Cultural and Economic Disengagement' in Altaf Gauhar (ed), South-South Strategy (London, Third World Foundation, 1983) 134-148. 
15. See Gupta $n 1$ above at $71-73,93-98$ and $132-134$.

16. See D. Pearce et al, 'The Social Costs of Climate Change' in J. Bruce et al (eds), Climate Change 1995: Economic and Social Dimensions of Climate Change (Contribution of Working Group III to the Second Assessment Report of the Intergovernmental Panel on Climate Change) (Cambridge, Cambridge University Press, 1996) 178-224.

17. See Joyeeta Gupta, North-South Aspects of the Climate Change Issue: Towards a Negotiating Theory and Strategy for Developing Countries paper prepared for the International Workshop organized by the Project to Enhance Policy-making Capacity Under the Framework Convention on Climate Change and the Kyoto Protocol, London, 17 March 1999.

18. See 'Eizenstat Addresses Climate Change Treaty Concerns' speech of the Under Secretary of State to the Association of Women in International Trade, 14 April 1998.

19. See Gupta, n 1 above, 177; and Gupta (1998), n 2 above, 187188.

20. Conference on Climate Assessment and Policy Development after Kyoto, organised by MIT Global Change Forum and the Royal Institute for Environmental Affairs in London, 16 June 1998.

21. Regional Workshop for Eastern and Southern Africa on the Clean Development Mechanism of the Kyoto Protocol to the United Nations Framework Convention on Climate Change, Organised by Climate Network Africa, 13-15 July 1998.

22. International Conference on Emission Scenarios and Mitigation Options in Asia: Scope for Meaningful Agreement, organized by Tata Energy Research Institute in New Delhi, 7-8 September 1998.

23. Debate on 'Schone Lucht in Buenos Aires' organized by the National Commissie Duurzaam Ontwikkeling in Utrecht on 28 October 1998

24. The International Workshop on Fair and Effective Regimes sponsored by the European Commission DG XII, during the fourth meeting of the Conference of the Parties in Buenos Aires, 3 November 1998

25. 'Beyond Growth: Policies and Institutions for Sustainability', conference organized by the International Society for Ecological Economics in Santiago, Chile, 16-20 November 1998.

26. Second European Forum on Integrated Environmental Assessment Policy Workshop on Integrating Climate Policies in the European Environment, Costs and Opportunities, Milan, 4-6 March 1999 and at the International Workshop organized by the Project to Enhance Policy-making Capacity Under the Framework Convention on Climate Change and the Kyoto Protocol, London, 17 March 1999.

27. See Gupta n 1 above, 194-200.

28. See Art 12, Kyoto Protocol and Jacob Werksman, 'The Clean Development mechanism: Unwrapping the "Kyoto Surprise"' RECIEL 7:2 (1998) 147-158.

29. See Art 17, Kyoto Protocol.

30. See eg FCCC/CP/1997/L.7, decision 5b.

31. UNCTAD, Controlling Carbon Dioxide Emissions: the Tradeable Permit System (Geneva, UNCTAD, 1995); A. Agarwal and S. Narain, Towards a Green World. Should Global Environmental Management be Built on Legal Conventions or Human Rights (New Delhi, Centre for Science and Environment, 1992); and H. Verbruggen, Global Sustainable Development: Efficiency and Distribution, Annual Report (Amsterdam, Institute for Environmental Studies, 1995)

32. See eg Art 3.2, UNFCCC.

33. See Tom Spencer, Climate Change and the G8: A Guide for Parliamentarians (London, The Globe Papers, 1997) and A. Agarwal and S. Narain, The Atmospheric Rights of all People on the Earth (New Delhi, Centre for Science and Environment, 1998).

34. Art 12, Kyoto Protocol.

35. A pilot phase on Activities Implemented Jointly was launched in the first meeting of the Conference of the Parties to the UNFCCC.

36. 'AIJ/JI The road from Rio to Kyoto', Joint Implementation Quarterly 3 (1997) 4.

37. 'Planned and Ongoing AIJ Pilot Projects', Quarterly Magazine on Joint Implementation 4 (1998) 14.

38. Sakona, Y.S. Humphreys and J-P Thomas, 'The Clean Development Mechanism: What Prospects for Africa?' (Dakar, Discussion paper - ENDA, 1998).

39. See, Council Conclusions on Climate Change, Council of Environmental Ministers, European Union, 3 March 1997; and Community Strategy on Climate Change - Council Conclusions, Council of Environmental Ministers, European Union, June 1998.

40. Fanny Missfeldt, 'Flexibility Mechanisms: Which Path to Take After Kyoto?' RECIEL 7:2 (1998) 128-139.

41. There are some rumours that Kazakhstan's decision to take on voluntary commitments was inspired by the 'hot air' discussions in relation to Ukraine and Russia.

42. David G. Victor and Julian E. Salt, 'Keeping the Climate Treaty Relevant' Nature 373 (1995) 280-282.

43. See also, Atiq Rahman et al, 'A New Initiative for North-South Dialog on Climate Change: Good Practices, Technology Innovation and New Partnership for Sustainable Development; Challenges and Opportunities in Implementing the Climate Convention' (Dhaka, Bangladesh Centre for Advanced Studies, 1997).

44. See eg A. Rahman and Francis Yamba, 'The South is Acting' ECO, 22 October 1997, 3.

45. See eg Gupta $n 1$ above, 58-71.

46. Art 12.8, Kyoto Protocol.

47. See the Protocol on Substances that Deplete the Ozone Layer (Montreal), 16 September 1987, in force 1 January 1989 (1987) 26 ILM 154.

48. Brazilian Proposal (1997), Proposed Elements of a Protocol, FCCC/AGBM/1997/Misc.1/Add.3, at 3.

49. See the Denver Communique of the G-7 countries of 1997.

50. See eg Gupta, n 1 above, 116-131.

Joyeeta Gupta is a senior researcher at the Institute for Environmental Studies, Amsterdam. The research undertaken for this paper is part of the long-term post-doctorate work being carried out in the project Climate Change: Regime Development in the Context of Unequal Power Relations financed by the Netherlands' Organisation for Scientific Research and a project financed by the Ministry of Housing, Spatial Planning and the Environment. The author thanks all those interviewed for sharing their time and vision. Some of the ideas in this paper have been tested in the course of the European Commission DG XII project on Fair and Effective Solutions: A proposal to enhance the policymaking process in the United Nations Framework Convention on Climate Change for DG XII of the European Commission. 